\title{
Neutrophil-to-lymphocyte ratio in patients with white-coat hypertension
}

\author{
(D)Esin Avşar, (1)Gökhan Tazegül, ĐErkan Çoban \\ ${ }^{1}$ Akdeniz University, Faculty of Medicine, Department of Internal Medicine, Antalya, Turkey
}

Cite this article as: Avşar E, Tazegül G, Çoban E. Neutrophil-to-lymphocyte ratio in patients with white-coat hypertension. J Health Sci Med 2021; 4(6): 824-827.

\begin{abstract}
Introduction: White coat hypertension (WCH), a distinct phenotype of hypertension, is defined as elevated office blood pressure (BP) measurements during repeat visits with normal out-of-office BP measurements. The association of WCH with cardiovascular risk remains unclear; however, current data support an association between untreated WCH and the risk for cardiovascular events, cardiovascular mortality, and all-cause mortality. Increased inflammatory processes may explain the underlying pathophysiology of the increased risk for cardiovascular events in $\mathrm{WCH}$; therefore, we evaluated the neutrophil-tolymphocyte ratio (NLR) of patients with WCH compared with matched normotensive controls.

Material and Method: Forty-five eligible subjects with WCH and 45 age, sex, and BMI matched healthy and normotensive subjects were included in the study. The subjects were assessed by office arterial BP and 24-hour ambulatory BP measurements. An automated blood count analyzer measured the NLR values.

Results: The mean NLR in the patients-with-WCH group was significantly higher than that in the control group ( $2.67 \pm 0.27 \mathrm{vs.}$ $2.46 \pm 0.34, \mathrm{p}<0.001$, Student's t-test); however, NLR was not correlated with BP measurements in either the WCH or control group.

Conclusion: NLR, a marker of inflammation, was increased in patients with WCH compared to the controls. Inflammation is a triggering mechanism for various cardiovascular and cerebrovascular events. Therefore, NLR has value as a potential independent risk factor that deserves further study, particularly in patients with WCH.
\end{abstract}

Keywords: High blood pressure, systemic hypertension, inflammation, neutrophil-to-lymphocyte ratio, white coat hypertension

\section{INTRODUCTION}

Hypertension is a major preventable cause of morbidity and mortality worldwide. Due to the increasing use of out-of-office blood pressure (BP) measurements, several distinct hypertension phenotypes have become apparent. One of these is white coat hypertension (WCH), defined as elevated office $\mathrm{BP}$ measurements during repeated visits with normal out-of-office BP measurements as assessed by home and/or 24-hour ambulatory BP monitoring measurements. Therefore, current guidelines recommend using out-of-office BP measurements to diagnose phenotypes, such as WCH (1). A systematic review demonstrated that the overall prevalence of $\mathrm{WCH}$, defined by 24-hour ambulatory BP measurements (ABPM), in the general population ranges from $5 \%$ to $65 \%$, and the prevalence increases with age (2-5).

Although hypertension is a well-established risk factor for morbidity and mortality, the association of $\mathrm{WCH}$ with cardiovascular risk remains unclear $(5,6)$. Several previous meta-analyses have reported weak to no associations of WCH with cardiovascular and all-cause mortality (7), especially for treated WCH (4); however, a recent metaanalysis revealed untreated $\mathrm{WCH}$, but not treated $\mathrm{WCH}$, as a risk factor for cardiovascular events, cardiovascular mortality, and all-cause mortality (8). An increase in atherosclerosis possibly causes this increase. Inflammatory processes are increasingly being recognized as playing a central role in the pathogenesis of atherosclerotic diseases and their complications (9). Elevated levels of systemic inflammatory markers have been found to be associated with cardiovascular diseases (10-12), and increased inflammatory processes may explain the underlying pathophysiology of the increased risk for cardiovascular events in WCH. Several previous studies have demonstrated an increase in novel inflammatory markers in $\mathrm{WCH}$ and sustained hypertension, such as high-sensitivity c-reactive protein (CRP), soluble CD40 ligand, procalcitonin, and pentraxin-3 (13-16). 
The neutrophil-to-lymphocyte ratio (NLR), routinely determined by complete blood count analysis, has emerged as a novel inflammation marker. It has been documented that NLR may predict inflammatory status for various cardiovascular risk factors, such as hypertension, diabetes mellitus, obesity, and smoking (17-19). Increased NLR is also associated with a poor prognosis of various cancers and ischemic heart disease (20-22). Although it has previously been shown that increased NLR is associated with essential hypertension and its complications, the relationship between NLR and $\mathrm{WCH}$ has not been previously studied (23-26). This study aimed to evaluate the NLR in patients with WCH compared with age-, sex-, and body mass index (BMI)matched normotensive controls.

\section{MATERIAL AND METHOD}

\section{Study Setting}

This cross-sectional case-control study was conducted in the internal medicine outpatient clinics of the local University Hospital per the Declaration of Helsinki. Approval for this study was obtained from Akdeniz University Medical School Non-Interventional Clinical Researchs Ethics Committee (Date: 08.07.2020, Decision No: 488). All patients provided written informed consent.

\section{Study Design and Participants}

This study aimed to evaluate patients with $\mathrm{WCH}$ compared to age-, sex-, and body mass index (BMI)matched normotensive controls. WCH was defined and diagnosed as a measured office BP of greater than 140/90 $\mathrm{mmHg}$ with an ambulatory measurement of less than $135 / 85 \mathrm{mmHg}$ (2). Healthy subjects, recruited from the routine check-up program of the local University Hospital, were used as a control group. Patients with sustained hypertension; diabetes mellitus (fasting glucose $>126$ $\mathrm{mg} / \mathrm{dL}$ or hemoglobin A1c $>6.5 \%$ ); a history of smoking or alcohol intake of more than $30 \mathrm{~g} /$ day; hyperlipidemia; obesity (BMI $\left.\geq 30 \mathrm{~kg} / \mathrm{m}^{2}\right)$; cardiac, renal, cerebral, and other systemic diseases; and recent major surgery or illness were excluded from the study. Hypertension was defined as systolic BP $\geq 140 \mathrm{mmHg}$ or diastolic BP $\geq 90 \mathrm{mmHg}$, as recommended by the $2013 \mathrm{ESH} / \mathrm{ESC}$ guidelines for the management of arterial hypertension (27). Hyperlipidemia was defined as the presence of at least one of the following conditions: increased plasma triglycerides $(>200 \mathrm{mg} / \mathrm{dL})$, total cholesterol $(>200 \mathrm{mg} /$ $\mathrm{dL})$, low-density lipoprotein cholesterol $(>130 \mathrm{mg} / \mathrm{dL})$, or decreased high-density lipoprotein cholesterol $(<40$ $\mathrm{mg} / \mathrm{dL}$ for men and $<50 \mathrm{mg} / \mathrm{dL}$ for women) (28). Fortyfive eligible subjects with $\mathrm{WCH}$ and 45 age-, sex-, and BMI-matched healthy and normotensive subjects were included in the final analysis.

\section{Assessment Instruments}

The subjects underwent a comprehensive assessment, including medical history, physical examination, and measurement of laboratory variables. Body weight and height were measured with the subjects wearing light clothes without shoes. BMI was calculated as the weight $(\mathrm{kg}) /$ height squared $(\mathrm{m})^{2}$. All the subjects' resting electrocardiograms were normal. A mercury sphygmomanometer was used to measure arterial BP after the patient had remained in a sitting position for $5 \mathrm{~min}$. For each subject, the average of three readings obtained within 5 min was recorded. For ABPM, a portable noninvasive recorder (SpaceLabs Medical Devices, Inc., Redmond, WA, USA) programed to record BP every 30 min for 24 hours was used for all measurements. This information was then used to calculate the average ambulatory BP over 24 hours for each subject. For laboratory evaluations, blood samples were collected from the antecubital vein without a tourniquet between 08:30 a.m. and 09:00 a.m. after overnight fasting. An automated blood count analyzer measured the total and differential blood cell counts. The NLR was calculated by dividing the absolute neutrophil count by the absolute lymphocyte count. Fasting plasma glucose, creatinine, alanine aminotransferase levels, c-reactive protein and lipid profiles were measured by enzymatic-colorimetric assays (Roche Diagnostic GmbH, Mannheim, Germany).

\section{Statistical Analyses}

SPSS statistical software (SPSS for Windows 16.0, Chicago, IL, USA) was used for the analyses. For a type 1 (a) error of 0.05 and a power of $80 \%$, a sample size per group of at least 36 subjects was needed to detect an actual difference. The normality of the distribution was determined by Shapiro-Wilk tests. NLR values between the groups were compared by Student's t-tests and Pearson's correlation coefficients. Data for categorical variables were presented as frequency and percentage, and continuous variables were expressed as mean $\pm S D$. Statistical significance was defined as $\mathrm{p}<0.05$.

\section{RESULTS}

Age, gender distribution, and BMI were similar between the WCH and control groups. Office systolic and diastolic BP measurements were significantly higher in patients with $\mathrm{WCH}(\mathrm{p}<0.001$, Student's t-test). The metabolic parameters in the study groups were similar as a result of the participant selection process. The mean NLR in the patients-with-WCH group was significantly higher than that in the control group $(2.67 \pm 0.27$ vs. $2.46 \pm 0.34, p<0.001$, Student's t-test). However, NLR was not correlated with $\mathrm{BP}$ measurements in the $\mathrm{WCH}$ and control groups (Spearman's rho correlation coefficient 0.16 and $0.09, \mathrm{p}$ value 0.14 and 0.42 , respectively) (Table). 
Table. Study group characteristics and laboratory results

\begin{tabular}{|c|c|c|}
\hline Parameters & $\begin{array}{c}\text { WCH group } \\
(n=45)\end{array}$ & $\begin{array}{c}\text { Control group } \\
(n=45)\end{array}$ \\
\hline Gender (men/women) & $45(21 / 24)$ & $45(22 / 23)$ \\
\hline Age (years) & $55 \pm 3$ & $55 \pm 2$ \\
\hline BMI $\left(\mathrm{kg} / \mathrm{m}^{2}\right)$ & $23.7 \pm 3.1$ & $23.6 \pm 3.2$ \\
\hline $\begin{array}{l}\text { Office systolic BP } \\
\text { measurement }(\mathrm{mmHg})\end{array}$ & $146 \pm 4.7^{\star *}$ & $127 \pm 5.1$ \\
\hline $\begin{array}{l}\text { Office diastolic BP } \\
\text { measurement }(\mathrm{mmHg})\end{array}$ & $94 \pm 5.3^{* * *}$ & $81 \pm 4.6$ \\
\hline $\begin{array}{l}\text { Fasting plasma glucose } \\
(\mathrm{mg} / \mathrm{dL})\end{array}$ & $86.8 \pm 9.7$ & $87.1 \pm 9.6$ \\
\hline Creatinine $(\mathrm{mg} / \mathrm{dL})$ & $0.9 \pm 0.2$ & $0.9 \pm 0.2$ \\
\hline $\begin{array}{l}\text { Alanine aminotransferase } \\
(\mathrm{U} / \mathrm{L})\end{array}$ & $25.7 \pm 3.5$ & $25.5 \pm 3.4$ \\
\hline C-reactive protein (mg/dL) & $0.23 \pm 0.11$ & $0.17 \pm 0.07$ \\
\hline Total cholesterol (mg/dL) & $169.4 \pm 21.9$ & $169.9 \pm 22.1$ \\
\hline LDL cholesterol (mg/dL) & $88.3 \pm 12.1$ & $88.9 \pm 11.6$ \\
\hline HDL cholesterol (mg/dL) & $48.7 \pm 5.4$ & $48.4 \pm 5.3$ \\
\hline Triglyceride (mg/dL) & $129.6 \pm 15.8$ & $128.9 \pm 16.3$ \\
\hline White blood cell $\left(\times 10^{3} / \mathrm{mm}^{3}\right)$ & $6.76 \pm 1.72$ & $6.69 \pm 1.74$ \\
\hline Neutrophil $\left(\times 10^{3} / \mathrm{mm}^{3}\right)$ & $4.74 \pm 1.55$ & $4.66 \pm 1.62$ \\
\hline Lymphocyte $\left(\times 10^{3} / \mathrm{mm}^{3}\right)$ & $1.81 \pm 0.19^{*}$ & $1.90 \pm 0.21$ \\
\hline $\begin{array}{l}\text { Neutrophil to } \\
\text { lymphocyte ratio }\end{array}$ & $2.67 \pm 0.27^{\star * *}$ & $2.46 \pm 0.34$ \\
\hline \multicolumn{3}{|c|}{$\begin{array}{l}\text { WCH: White coat hypertension, BMI: Body mass index, BP: Blood pressure, LDL: } \\
\text { low-density lipoprotein; HDL: high-density lipoprotein. }{ }^{*} \mathrm{p}<0.05,{ }^{* *} \mathrm{p}<0.01 \text {, and } \\
{ }^{* * *} \mathrm{p}<0.001 \text {, Student's t-test, WCH group vs. control group. }\end{array}$} \\
\hline
\end{tabular}

\section{DISCUSSION}

Hypertension is a well-established risk factor for morbidity and mortality, possibly due to its' relation with atherosclerosis. Atherosclerosis is characterized by a complex multifactorial pathophysiology. Inflammatory processes in vessel walls are increasingly recognized as playing a central role in the initiation, progression, and final steps of atherosclerosis $(9,29)$. WCH, a distinct phenotype of hypertension, was recently demonstrated as a risk factor for cardiovascular events, cardiovascular mortality, and all-cause mortality, especially if left untreated $(4,8)$. Several inflammatory markers have been shown to be increased in WCH (14-16), but the relationship between NLR and $\mathrm{WCH}$ has not been previously studied. In this matched case-control study, we aimed to evaluate the NLR in patients with $\mathrm{WCH}$ compared to age-, sex-, and body mass index (BMI)matched normotensive controls. We excluded patients with several confounding factors such as sustained hypertension, diabetes mellitus, smoking or alcohol intake, hyperlipidemia, obesity, cardiac, renal, cerebral, and other systemic diseases, and recent major surgery or illness. In this study population, we have demonstrated that NLR was increased in patients with $\mathrm{WCH}$, compared to age-, sex-, and body mass index (BMI)-matched normotensive controls.
There are several studies in the literature on the relationship between inflammation, including NLR, and essential hypertension (23-26). However, there are limited studies about the relationship between systemic inflammation markers and WCH. Ozdogan et al. (14) reported that in patients with $\mathrm{WCH}$, high-sensitivity CRP, a marker of low-grade inflammation, is higher than normotensive patients, whereas in patients with essential hypertension, high-sensitivity CRP levels were even higher than in patients with WCH. Andrikou et al. (30) confirmed higher high-sensitivity CRP levels and demonstrated that $\mathrm{WCH}$ is also associated with arterial stiffening compared with normotensive patients. Similarly, several studies have also reported increased soluble CD40 ligand, procalcitonin, and pentraxin-3 levels in WCH compared to normotensive groups (14-16).

Neutrophil-to-lymphocyte ratio is a novel, non-invasive, easily-calculable, and easily obtained marker as a surrogate for inflammation. NLR has been previously studies and in many hemato-oncologic, immunologic and infectious diseases as well as cardiologic disorders, and the increase has been associated with increased morbidity and mortality. It has been well documented that NLR is associated with increased inflammatory status for various cardiovascular risk factors and essential hypertension and its complications (17-19,23-26). Herein, we add to the literature that an increase in NLR is seen in patients with in $\mathrm{WCH}$, compared to controls, as a novel marker of inflammation. Although WCH as a risk factor for cardiovascular events, cardiovascular mortality, and all-cause mortality is still of debate, an increase in NLR as a surrogate for increased inflammation may suggest that patients with $\mathrm{WCH}$ are also at risk for cardiological disorders such as ischemic heart disease.

This study has certain limitations. First, the sample size was small, although higher than the calculated sample size; nevertheless, both groups were homogeneous in terms of age, gender, BMI, and laboratory results. Second, due to the case-control study design, the results may not reflect long-term effects. Third, these findings are limited to a homogeneous group of patients, so the results may not apply to all patients with WCH.

\section{CONCLUSION}

We have demonstrated that NLR, a marker of systemic inflammation, was increased in patients with WCH compared to controls. Inflammation is a triggering mechanism for various cardiovascular and cerebrovascular events; therefore, NLR has value as a potential independent risk factor that deserves further study, particularly in patients with WCH. 


\section{ETHICAL DECLARATIONS}

Ethics Committee Approval: Approval for this study was obtained from Akdeniz University Medical School Non-Interventional Clinical Researchs Ethics Committee (Date: 08.07.2020, Decision No: 488).

Informed Consent: All patients signed the free and informed consent form.

Referee Evaluation Process: Externally peer-reviewed.

Conflict of Interest Statement: The authors have no conflicts of interest to declare.

Financial Disclosure: The authors declared that this study has received no financial support.

Author Contributions: All of the authors declare that they have all participated in the design, execution, and analysis of the paper, and that they have approved the final version.

\section{REFERENCES}

1. Muntner P, Shimbo D, Carey RM, et al. Measurement of blood pressure in humans: a scientific statement from the American Heart Association Hypertension 2019; 73:e35-e66.

2. Cuspidi C, Sala C, Grassi G, Mancia G. White coat hypertension: to treat or not to treat? Curr Hypertens Rep 2016; 18: 80.

3. Campbell PT, White WB. Utility of ambulatory blood pressure monitoring for the management of hypertension. Curr Opin Cardiol 2017; 32: 365-72.

4. Huang Y, Huang W, Mai W, et al. White-coat hypertension is a risk factor for cardiovascular diseases and total mortality. J Hypertens 2017; 35: 677-88

5. Piper MA, Evans CV, Burda BU, Margolis KL, O'Connor E, Whitlock EP. Diagnostic and predictive accuracy of blood pressure screening methods with consideration of rescreening intervals: a systematic review for the U.S. Preventive Services Task Force. Ann Intern Med 2015; 162: 192-204.

6. Franklin SS, Thijs L, Asayama K, et al. Cardiovascular risk in white-coat hypertension. JACC 2016; 68: 2033-43.

7. Briasoulis A, Androulakis E, Palla M, Papageorgiou N, Tousoulis D. White-coat hypertension and cardiovascular events: a metaanalysis. J Hypertens 2016; 34: 593-9.

8. Cohen JB, Denker MG, Cohen DL, Townsend RR. Cardiovascular events and mortality in white coat hypertension. Ann Intern Med 2019; 171: 603-4.

9. Blake GJ, Ridker PM. Inflammatory bio-markers and cardiovascular risk prediction. J Intern Med 2002; 252: 283-94.

10. Ridker PM. Inflammation, atherosclerosis, and cardiovascular risk: an epidemiologic view. Blood Coagul Fibrinolysis 1999; 10: 9-12.

11. Rifai N. C-reactive protein and coronary heart disease: diagnostic and therapeutic implications for primary prevention. Cardiovasc Toxicol 2001; 1: 153-7.

12. Benzaquen LR, Yu H, Rifai N. High sensitivity C-reactive protein: an emerging role in cardiovascular risk assessment. Crit Rev Clin Lab Sci 2002; 39: 459-97.

13. Ridker PM. High-sensitivity C-reactive protein and cardiovascular risk: rationale for screening and primary prevention. Am J Cardiol 2003; 92: 17K-22K.

14. Ozdogan M, Bozcuk H, Coban E. Low-grade inflammation in white-coat hypertension. Med Sci Monit 2007; 13: CR570-573.
15. Yavuzer H, Cengiz M, Yavuzer S, et al. Procalcitonin and Pentraxin-3: current biomarkers in inflammation in white coat hypertension. J Hum Hypertens 2016; 30: 424-9.

16. Huang YQ, Jie LI, Chen JY, Tang ST, Huang C, Feng YQ. The relationship between soluble CD40 ligand level and atherosclerosis in white-coat hypertension. J Hum Hypertens 2017; 32: 40-5.

17.Imtiaz F, Shafique K, Mirza SS, Ayoob Z, Vart P, Rao S. Neutrophil lymphocyte ratio as a measure of systemic inflammation in prevalent chronic diseases in Asian population. Int Arch Med 2012; 5: 2 .

18.Guo X, Zhang S, Zhang Q, et al. Neutrophil:lymphocyte ratio is positively related to type 2 diabetes in a large-scale adult population: a Tianjin chronic low-grade systemic inflammation and health cohort study. Eur J Endocrinol 2015; 173: 217-25.

19. Azab B, Camacho-Rivera M, Taioli E. Average values and racial differences of neutrophil lymphocyte ratio among a nationally representative sample of United States subjects. PloS One 2014; 9: e112361.

20. Templeton AJ, McNamara MG, Šeruga B, et al. Prognostic role of neutrophil-to-lymphocyte ratio in solid tumors: a systematic review and meta-analysis. J Natl Cancer Inst 2014; 106: dju124.

21. Verdoia M, Barbieri L, Giovine GD, Marino P, Suryapranata H, De Luca G. Neutrophil to lymphocyte ratio and the extent of coronary artery disease: results from a large cohort study. Angiology 2016; 67: 75-82.

22. Erturk M, Cakmak HA, Surgit O, Celik O, Aksu HU. The predictive value of elevated neutrophil to lymphocyte ratio for long-term cardiovascular mortality in peripheral arterial occlusive disease. J Cardiol 2014; 43: 61-9.

23. Liu X, Zhang Q, Wu H, et al. Blood neutrophil to lymphocyte ratio as a predictor of hypertension. Am J Hypertens 2015 28: 1339-46.

24. Yayla C, Canpolat U, Akyel A, et al. Association of neutrophillymphocyte ratio with impaired aortic elasticity in newly diagnosed and never-treated hypertensive patients. Blood Press Monit 2015; 20: 127-31.

25. Karagoz A, Vural A, Gunaydin ZY, et al. The role of neutrophil to lymphocyte ratio as a predictor of diastolic dysfunction in hypertensive patients. Eur Rev Med Pharmacol Sci 2015; 19; 433 40.

26. Demir M. The relationship between neutrophil lymphocyte ratio and non-dipper hypertension. Clin Exp Hypertens 2013; 35: 570 3.

27. Mancia G, Fagard R, Narkiewicz K, et al. Task Force for the management of arterial hypertension of the European Society of Hypertension and the European Society of Cardiology. Blood Press 2014; 23: 3-16.

28. Expert Panel on Detection, Evaluation, and Treatment of High Blood Cholesterol in Adults (Adult Treatment Panel III). Executive Summary of the Third Report of the National Cholesterol Education Program (NCEP). JAMA 2001; 285: 2486-97.

29. Shrivastava AK, Singh HV, Raizada A, Singh SK. C-reactive protein, inflammation and coronary heart disease Egypt Heart J 2015; 67: 89-97.

30. Andrikou I, Tsioufis C, Dimitriadis K, et al. Similar levels of lowgrade inflammation and arterial stiffness in masked and whitecoat hypertension: comparisons with sustained hypertension and normotension. Blood Press Monit 2011; 16: 218-23. 